\title{
Highlights
}

- Model predicts AIS data reception in the majority of Scottish coastal waters.

- Open source software provides a useful and effective platform for AIS data analyses.

- AIS data facilitates incorporation of small scale fisheries into spatial planning.

- AIS data useful to characterise fishing trips and most important fishing grounds.

- Important limitations of using AIS data for regulatory purposes identified. 


\title{
AIS data to inform small scale fisheries management and marine spatial planning
}

\begin{abstract}
Automatic Identification Systems (AIS) are collision avoidance devices used on-board both commercial and leisure craft. These systems report the position, track and speed of the vessel through Very High Frequency radio transmissions which are accessible to any suitable receiver. This paper explores the potential to use AIS data to inform small scale fisheries management and marine spatial planning. First, the propagation and reception of the line of sight AIS transmissions was modelled around the coast of Scotland to identify areas where the use of AIS may be compromised. Using open source Geographic Information System and relational database software, computationally efficient methods of processing and analysing AIS data were explored. Three months of AIS data derived from 274 Scottish small scale fishing vessels were used to provide spatio-temporal analyses of trip duration and distance travelled, location of fishing activities, and vessel dependency on fishing grounds. The coverage, opportunities and challenges of using AIS are discussed together with broader applications and future developments.
\end{abstract}




\section{AIS data to inform small scale fisheries management and marine spatial planning}

Mark James $^{1 \$}$, Tania Mendo ${ }^{1 \$^{*}}$, Esther L. Jones ${ }^{23}$, Kyla Orr ${ }^{4}$, Ali McKnight ${ }^{5}$, John Thompson ${ }^{1}$

1. Scottish Oceans Institute, University of St. Andrews. East Sands, Fife UK, KY16 LB

2. School of Applied Sciences, University of South Wales, Cemetery Road, Glyntaff, Pontypridd, CF37 $4 B D$

3. Centre for Research into Environmental and Ecological Modelling, School of Mathematics and Statistics, University of St Andrews, The Observatory, Buchanan Gardens, St Andrews, Fife, UK, KY16 9LZ

4. Marine Ecological Consulting, Corkil, Plockton, UK, IV52 8TU

5. Agroecosystems Ltd, Keeper's House, Gaick, Kingussie Inverness-shire UK PH21 1NZ

*Corresponding author

${ }^{\$}$ These authors contributed equally to this work

Conflicts of interest: none. 
1 AIS data to inform small scale fisheries management and marine spatial planning

2

3 Abstract

4

5 Automatic Identification Systems (AIS) are collision avoidance devices used on-board both 6 commercial and leisure craft. These systems report the position, track and speed of the vessel 7 through Very High Frequency radio transmissions which are accessible to any suitable receiver.

8 This paper explores the potential to use AIS data to inform small scale fisheries management 9 and marine spatial planning. First, the propagation and reception of the line of sight AIS transmissions was modelled around the coast of Scotland to identify areas where the use of AIS may be compromised. Using open source Geographic Information System and relational database software, computationally efficient methods of processing and analysing AIS data were explored. Three months of AIS data derived from 274 Scottish small scale fishing vessels were used to provide spatio-temporal analyses of trip duration and distance travelled, location of fishing activities, and vessel dependency on fishing grounds. The coverage, opportunities and challenges of using AIS are discussed together with broader applications and future developments.

Keywords: monitoring, inshore fisheries, trips, PostgreSQL, trajectories

\section{Introduction}

Marine spatial planning is a process that improves decision making through the allocation of uses to the marine environment to achieve ecological, economic, and social objectives. Fishing activities are reliant on the marine environment, have considerable socio-economic importance and contribute to food security [1, 2]. Increasing competition for space use in the marine environment [3] drives the need to map fishing activities to inform marine planning and meet policy commitments. In Europe, these commitments include the development of Marine Protected Areas (MPAs) and MPA networks [4], which can displace fishing activities [5], the installation of marine renewable energy devices which can exclude certain types of fishing gear [6], expansion of aquaculture, and marine related leisure activities. Assessing the spatiotemporal distribution of fishing activities can inform managers of fisheries interactions with the environment [7] and this information is needed to achieve Good Environmental Status (GES) under the Marine Strategy Framework Directive [4]. 
Fishers have been traditionally reluctant to share information on where they fish, but a combination of regulation, and market demands will require fishers to demonstrate that they are fishing stocks within safe biological limits and in areas where they are permitted to do so (e.g. an increasing number of retailers are adapting their buying policies to exclude nonsustainable products [8]). Conflicts between competing users of marine space are increasing [3]. Balancing the trade-offs between these activities requires an objective evidence base of spatio-temporal use, environmental, social and economic impact. Both resource users and those that regulate their activities will require these data as historic and contemporary records to support continued use and assess competing claims.

Small scale inshore fishing vessels (12 $\mathrm{m}$ and under) (SSF) represent over $80 \%$ of the total fleet in almost all European Union Member States [9]. In many cases, SSF data that are currently available are insufficient to determine fishing effort and the status of targeted stocks. SSF are important in terms of their contribution to local economies, food security, trade and their contribution to resilience of small scale business and social cohesion in Europe's coastal communities [9]. Therefore, analysis of spatio-temporal activities of SSF needs to be incorporated into marine spatial planning considerations (as is the case with Scotmap in Scotland [10] and in the Shetland Islands with their Marine Spatial Plan [11]), the EU's Data Collection Framework (DCF) and strategic policy development.

Previous studies of space utilisation and fishing activities in SSF vessels have been based on interviews with experts, sightings from shore, logbook data, fisheries protection vessels and aircraft patrolling, or combining multiple criteria and information sources [12-15]. These approaches provide imprecise information to fisheries management and marine planning as they are often based on records of limited duration, the location of the vessels over time is insufficiently spatially resolved for use in inshore areas and they are of limited or no value in determining fishing effort or fleet responses to management actions [13]. Vessel monitoring systems (VMS) are required for all licensed European Union (EU) fishing vessels over $12 \mathrm{~m}$ and Automatic Identification Systems (AIS) Class A transceivers have to be installed in fishing vessels over $15 \mathrm{~m}$ [16], providing higher resolution data on fishing activity. Publicly accessible vessel reporting systems such as AIS provides an alternative source of data that can be used to inform fisheries management and marine planning [17-19]. AIS utilises ship to ship very high frequency (VHF) electromagnetic wave transmission and line-of-sight reception. Subject to 
range limitations, AIS transmissions can be received by other ships equipped with AIS or any suitable ground based or Low Earth Orbit (LEO) satellite receiver, making AIS data more accessible and less expensive to transmit than VMS data which is usually based on point to point satellite communication between the vessel and the ground centres [18]. In addition, AIS data is of higher spatial resolution than conventional VMS fitted to vessels over $12 \mathrm{~m}$ and of comparable resolution to inshore VMS [20]. Inshore Vessel Monitoring System (iVMS) are now being deployed in some $\leq 12 \mathrm{~m}$ inshore fishing vessels [e.g. 21]. These units provide a much more robust overall package with respect to security of units and data, accessibility to managers, and availability of integrating plug-ons for catch reporting than can be gained from AIS alone. However, unlike AIS, iVMS track data is not publicly available.

As AIS was originally conceived as a vessel safety system for collision avoidance rather than data acquisition, data collection and processing differs from VMS and requires additional considerations. Recent studies have highlighted the potential use of AIS as a tool for marine spatial planners and outlined methodologies for processing AIS data [17, 18, 22, 23]. As SSF generally operate closer to shore, the feasibility of utilising such systems for data collection needs to be evaluated because the coverage of AIS receivers is not homogeneous and complex coastal topography may impair line of sight detection of AIS targets. The challenges of storing, applying quality control filters, querying and mapping large volumes of positional data that are likely to be produced by the large number of SSF vessels in Europe have thus far not been adequately addressed. There is a need to develop procedures to manage and integrate vessel movement data sets and link these data with relevant effort metrics to inform fisheries management.

This study focused on inshore fishing vessels around Scotland, UK, operating within Scottish Territorial waters (within 12 nautical miles (NM) of the coast), where spatio-temporal information on the distribution of vessels is lacking, especially in areas that are remote and have limited access (e.g. outer islands). Vessels $\leq 12 \mathrm{~m}$ dominate the Scottish fleet; in 2016, 1508 vessels ( $\sim 78.5 \%$ of all Scottish fishing vessels) were $\leq 12 \mathrm{~m}$ compared with $413>12 \mathrm{~m}$ vessels [24]. The aim of the study was to determine the feasibility of utilising AIS data as a tool for informing fisheries management and marine spatial planning with respect to SSF in Scotland and to consider the wider implications of using these data for compliance purposes. This included the assessment of AIS transmitter coverage and the development of a relational database to collate and analyse inshore fishing activity data. A total of 274 small scale fishing 
vessels ( $\sim 18 \%$ of the $\leq 12 \mathrm{~m}$ fleet) were voluntarily equipped with Class B AIS in June/July 2015. AIS Class B transceivers are lower cost alternatives to Class A and their transmission or ping rate is usually every 30 seconds whilst the vessel is in transit, but this can be reduced to 3 minutes when anchored or moored and 6 minutes when static [19]. Three distinct areas were then selected as case studies to evaluate the potential applications of AIS data in the context of SSF.

\section{Methods}

111

\subsection{Assessment of coverage}

113

The VHF transmissions utilised by AIS operate on line of sight and therefore any obstruction between the transmitter and receiver may result in transmission being impaired or blocked. The purpose of this study was to assess the utility of using terrestrial AIS receivers which are either land based Base Stations or attached to fixed assets at sea (Aids to Navigation - AtoNs). The range of VHF transmission is determined by a combination of factors: distance between the transmitter and receiver (provided there is clear line of sight), transmitter/transmission power, aerial height and quality, receiver sensitivity, and atmospheric conditions. Assessment of AIS coverage around Scotland was estimated following methods described in [25]. In summary, using the CloudRF online radio frequency planning software (https://cloudrf.com), the Base Station and AtoNs data [26], together with the AIS system specifications data were uploaded to the CloudRF online system and a Longley Rice Irregular Terrain Model (ITM) [27] was used to predict their respective range of reception. The model used high resolution $30 \mathrm{~m}$ Shuttle Radar Topography Mission (SRTM) data that include ground elevation and although this does not take into account buildings or other artificial structures this is not generally a concern for the coastal areas of Scotland, where population densities and built structures are sparse.

\subsection{AIS data}

A total of 274 inshore fishing vessels were equipped with Class B AIS (XB8000 transponder and GPS and VHF antenna produced by Vespermarine, Auckland, New Zealand) in June/July 2015. For the duration of the project, the AIS units were installed and powered through a direct connection to the vessels main switches to ensure that the AIS units were transmitting all the time that the vessels main switches were on. The AIS units silent mode was disabled. The 
vessels fitted with AIS units were distributed around the Scottish coast as follows: $47 \%$ operated from the East coast (30 home ports), 22\% from the West coast (30 home ports), 16\% from the Outer Hebrides (19 home ports), 14\% from Shetland (10 home ports) and 2\% from the North Coast (4 home ports) [28]. The majority of vessels fitted with AIS units operated static gear (84\%), followed by mobile gear (14\%) and a few operated both mobile and static gear (2\%). The static gear vessels predominantly fished using creels to target European lobster (Homarus gammarus), brown crab (Cancer pagurus), velvet crab (Necora puber) and Norway lobster (Nephrops norvegicus) (175 vessels). However, an additional 56 'static gear vessels' also fished using lines and/or nets, either exclusively or in combination with creels. Of the mobile gear vessels, 31 were bottom trawlers that exclusively targeted Norway lobsters, 4 were scallop dredgers, 4 utilised a combination of dredges and bottom trawls, and 4 Norway lobster trawlers also deployed static gear [28]. Fishers gave consent for their data to be used in anonymised form for the purposes of this research. Received AIS transmissions from the SSF vessels fitted with this system together with all other vessels designated under their Maritime Mobile Service Identity (MMSI) number as being fishing vessels was harvested by UltraMap Ltd (http://www.ultra-map.org/) between August 2015 and October 2015. The resulting dataset comprised more than 37 million rows of information, including unique id; time stamp; longitude; latitude; MMSI; vessel name; speed over ground; course over ground; true heading; navigational status; draught, and destination. For the purposes of this study, however, only data from the SSF vessels fitted with this system were analysed.

A Javascript was used to automatically transfer data from csv files $(\sim 4,320$ per month) to a unique table. A spatial component was then added and duplicates were flagged based on time and position using PostgreSQL with PostGIS on a desktop computer (Intel ${ }^{\circledR}$ Core $^{\mathrm{TM}}$ i7-5820K @3.30GHz with 32Gb RAM x64-bit Windows 10 Pro OS). Further analysis was conducted in $\mathrm{R}$ [29] using the library RPostgreSQL [30], an interface to the PostgreSQL database system (see flow diagram in Appendix C, Fig. C1). A table related by vessel MMSI was also created containing ancillary vessel information including: type of fishing method used; main target species; name of skipper; name of vessel; coastal region; administrative district; home port; and the date of install of the AIS system.

Three Administrative Districts (AD; areas encompassing several landing ports) were selected. Only static gear vessels (commercial inshore fishing vessels $\leq 12 \mathrm{~m}$ using creels and pots) were analysed to avoid potential differences in operational characteristics caused by gear variation. 
171 Districts were selected to represent geographically distinct regions with varied topography, high landings of brown crab and European lobster and high fisher participation rates: Anstruther (Fife) $\left(56^{\circ} 13^{\prime} 14.5^{\prime \prime} \mathrm{N} 2^{\circ} 41^{\prime} 54.5^{\prime \prime} \mathrm{W}\right)$, east Scotland recorded the highest landings of European lobster in 2014 [31]; Stornoway (58 12'33.8"N 6²3'30.5"W) encompassing several islands of the Outer Hebrides, and Lerwick $\left(60^{\circ} 09^{\prime} 13.5^{\prime \prime} \mathrm{N} 1^{\circ} 08^{\prime} 31.0^{\prime \prime} \mathrm{W}\right)$ representing the archipelago comprising the Shetland Islands both recorded high landings of brown crabs [31]. A subset of 82 vessels (Fife $=21$; Outer Hebrides $=41$; Shetland=20) generated 1.2 million AIS records from August 2015 - October 2015. As participation in this study was voluntary, the number of vessels taking part was not representative of the total number of vessels in each AD. The main species targeted by these vessels were European lobster, brown crab, velvet crab, and Norway lobster.

182

\subsection{Potential applications for fisheries management and marine spatial planning} 184

\subsubsection{Trip duration and distance travelled}

186

187 Data were pre-processed and a series of criteria were applied to vessel tracks to delimit each 188 fishing trip. The temporally ordered sequence of spatio-temporal AIS position records was analysed using the adeHabitatLT package [32]. To ensure "continuity" in the use of AIS units, only vessels for which total tracking duration (time elapsed between the first and last 
206 Vessels were almost exclusively fishing during daylight hours (only $0.5 \%$ of all the AIS 207 records were transmitted between 21:30 and 05:30 hours - Appendix A, Fig. A2), therefore, for each particular date for each vessel, the time gap between observations was visually assessed. $99.99 \%$ of the time gaps between consecutive observations in a particular day were less than 3 hours long, therefore a time interval of more than three hours without the receipt of an AIS record was deemed indicative of a vessel switching off the AIS unit at the end of a fishing trip. This value was also chosen based on the rationale that a fishing trip in which there was a gap of 3 hours without information would result in underestimation of total distance travelled. Speed values were calculated by dividing distance by time for two consecutive locations. Unrealistic speeds greater than 40 knots were excluded. It was assumed that a minimum of 12 locations were needed to describe a fishing trip: 3 steaming from port, 6 to characterise a creel deployment pattern, and 3 when steaming back to port. Therefore, only tracks with 12 or more locations were retained.

Trips in which the total distance travelled was less than $300 \mathrm{~m}$ were removed (a conservative estimate of the average minimum distance required to transit in and out of a fishing port). More than $90 \%$ of the trips started and ended less than 500 metres away from the coast, therefore, to reduce underestimation of trip duration and distance travelled, only tracks where both the start and end points were less than 500 metres from the coast were retained. This criterion was modified to 1000 metres for Anstruther, where vessels typically tended to shut down their engines, and thus power off their AIS units, while waiting for the tide to turn to allow access to the harbour. It is important to note that many $12 \mathrm{~m}$ and under fishing vessels are equipped with batteries that have limited capacity or are in poor condition. As a consequence most AIS units were fitted to vessels in such a manner as to ensure that they only received power when the engine was running, thereby minimising the risk of depleting the batteries charge.

Trip duration was calculated as the difference between the start and end date and time for each track. Total distance travelled was calculated by adding the straight-line distances between consecutive locations in each track. Differences in trip duration and distance travelled among the three regions were explored using an ANOVA, followed by a post-hoc Tukey test. Normality and homogeneity of error within groups was assessed using a ShapiroWilks and Bartlett test respectively. A track was considered to be an individual fishing trip if 
there was a start and end location in close proximity to the coast. Intermediate locations within each track concentrated close to each other usually forming a "looping pattern" (see

241 Fig. 1c), were indicative of a vessel drifting during creel recovery. This was supported by observer's data, where for 6 fishing trips in 6 different vessels, time of steaming, hauling of gear and gear re-deployment was recorded. Observer's used a handheld GPS unit (Garmin Etrex 20x) set at polling intervals of 10 seconds (Appendix B, Fig B1).

\subsubsection{Location of fishing activities}

247

To identify fishing activities within the data, observations where speed over ground (SOG) ranged from $>0.0-3.0$ knots were retained. This threshold was defined through inspection of observer's data (Appendix B, Fig B2 and through consultation with fishermen). After visual inspection, spatial buffer zones of 100 metres were set around landing ports to avoid incorporating locations with low speeds as a result of transiting harbour areas. This conservative threshold was based on observations of vessels deploying gear at distances $<300 \mathrm{~m}$ from port (Mendo, pers. obs). Tracks were then divided when speeds between consecutive observations were $>3$ knots, as this was indicative of a vessel switching from fishing to other activities. The maximum spatial gap permitted between two consecutive AIS records was 1000 metres and the maximum temporal gap between consecutive AIS locations was set to 15 258 minutes.

260 Fishing activity levels were standardised by regularly sampling linearly interpolated locations every 2.5 minutes. Fishing activity levels were calculated for each vessel by month in each grid cell (1000 metres x 1000 metres) as the total number of hours spent fishing. Locations from each vessel by month were kernel smoothed to transform them into a density surface. The ks library in R [33] estimated 2D bandwidths applied to locations from each vessel using an unconstrained plug-in selector (Hpi), and kernel density estimator (kde) to fit a density surface, which was normalised to one. Kernel smoothing can be sensitive to the choice of smoothing parameter and serial correlation in the observations. However, thinning the data to eliminate autocorrelation would have meant a significant loss of information. Instead, the total duration of tracks per vessel (Fife $\mu=60.20 \mathrm{~h}, \sigma=40.08 \mathrm{~h}$; Shetland $\mu=75.65, \sigma=66.09$; Outer Hebrides $\mu=101.95, \sigma=62.96 \mathrm{~h}$ ) were determined to be long enough to counteract bandwidth sensitivity [34]. Each density surface was multiplied by the number of hours the vessel spent 
fishing during the month. Fishing activity levels were calculated by aggregating all density surfaces by AD during each month.

274

\subsubsection{Vessel dependency on fishing grounds}

To identify which grid cells were used by multiple vessels, the number of vessels fishing in each grid cell (1000 metres x 1000 metres) was calculated by month for each AD. The resulting map was not scaled by fishing activity levels but rather identified the importance of areas where multiple vessels spent time fishing.

\section{Results}

\subsection{AIS coverage and data management}

The AIS reception model suggests that the majority $(\sim 85 \%)$ of Scottish Territorial waters are covered (Fig. 1). Discrete areas such as within sea lochs, west of Skye, outer Moray Firth, Firth of Forth, and north-west coast of the mainland show poor predicted reception (Fig. 1), which may require more detailed investigation. In areas with low predicted reception, scarcity of AIS records resulted in failure to identify individual fishing trips (Fig. 2a). However, in areas where the predicted reception was high, individual fishing trips could be identified for each vessel (Fig. 2b).

\#\#\#\#\#\#ig. 1 here

\#\#\#\#\#\#ig. 2 here

The transfer of data from csv files to a unique table in PostgreSQL, addition of a spatial component, and removal of duplicates based on time and position was feasible using PostgreSQL with PostGIS. Further analysis was conducted in R using RPostgreSQL, an interface to the PostgreSQL database system (see flow diagram in Appendix C, Fig. C1 and computational times required in Appendix C, Table C1). The transmission rate of Class B AIS is usually every 30 seconds whilst the vessel is in transit, but this can be reduced to 3 minutes when anchored or moored and 6 minutes when static [19]. The data showed this frequency of AIS records in vessels from the Outer Hebrides and Shetland. However, for vessels located in 
306 Fife, the frequency of AIS records ranged from 5-7 minutes even when vessels were clearly in transit.

308

\subsection{Potential applications for fisheries management and marine spatial planning} 310

Mean trip duration showed regional differences (Fig. 3a), vessels in the Outer Hebrides generally conducted longer trips $(7.49 \mathrm{~h}[6.98-8.01 \mathrm{CI}])$ compared to vessels in Fife and Shetland $(5.1 \mathrm{~h}[4.22-5.98 \mathrm{CI}]$ and $5.44 \mathrm{~h}[4.71-6.17 \mathrm{CI}]$, respectively, ANOVA F=16.129, $\mathrm{df}=2,74, \mathrm{p}<0.001$ ). Mean distance travelled per trip for each vessel again showed regional variation (Fig. 3b, ANOVA $F=5.11 ; d f=2,74 ; p<0.01$ ). The mean distance travelled for vessels in the Outer Hebrides was greater $(36.8 \mathrm{~km}$ [32.06 - 51.57 CI]) than the distance travelled by vessels in Fife $(24.9 \mathrm{~km}$ [17.92 - $31.91 \mathrm{CI}])$. There was no significant difference between distance travelled in Fife and in Shetland (28.2 km [23.09 - 33.43 CI]).

The set of criteria used to identify fishing trips showed low error rates (Outer Hebrides $=9.4 \%$, Shetland $=10.4 \%$, Fife $=10.5 \%$ ). The main reasons for error in identification of trips were either poor AIS coverage (which made it difficult to identify the characteristic looping pattern of static gear recovery) or two or more fishing trips being incorrectly identified as one. This occurred on 32 occasions from 1037 trips (Outer Hebrides), 9 out of 519 trips (Shetland), and 18 from 429 trips, (Fife) where the gaps between successive trips was less than 3 hours. Due to the greater gap between consecutive AIS records in Fife, it proved more challenging to identify individual fishing trips (see Fig. D1 in Appendix D).

\#\#\#\#\#\#Fig. 3 here

\subsubsection{Fishing activity}

Average fishing activity per vessel exhibited monthly variation in all $\mathrm{AD}$, with an overall decrease in time spent fishing from August to October, while the number of vessels engaged in fishing activity remained fairly constant (Table 1). Average fishing activity per month per vessel varied from $18.67 \mathrm{~h}$ to $40.15 \mathrm{~h}$ across districts. In Fife, from August to October, most fishing activities focussed near shore, with some exploration of fishing grounds further offshore. During October, fishing activities were spread out over previously explored fishing grounds, (those that had been fished in August and September) (Fig 4 a-c). In Shetland, fishing 
activities concentrated in the same areas from August to October (Fig. 4 d-f). In the Outer

341 Hebrides, while fishing activities occurred on both the western and eastern side of the islands 342 during August and September, in October, activities concentrated more on the Eastern side 343 (Fig. 4 g-i).

\subsection{AIS data: coverage, opportunities and challenges}

\section{\#\#\#\#\#Fig. 4 here}

\subsubsection{Vessel dependency on fishing grounds}

Within the fishing grounds identified above and irrespective of fishing effort, some areas were used by a greater number of fishing vessels than others. This is the case in Fife where a greater number of vessels are dependent on nearshore areas with only a small proportion travelling to areas further offshore (Fig. 5 a-c). In Shetland, the number of vessels using fishing grounds decreased as the season progressed (Fig. 5 d-f). In the Outer Hebrides, there was a southward shift of vessels towards more central areas as well as clear movement from western to Eastern areas (Fig. 5 g-i). Shetland and the Outer Hebrides showed a more patchy distribution of fishing vessels compared to Fife.

\#\#\#\#\#\#Fig. 5 here

\section{Discussion}

This study demonstrates that AIS data can provide a valid tool to inform fisheries management and marine spatial planning within the context of SSF, focusing on Scottish $\leq 12 \mathrm{~m}$ static gear vessels. The collated AIS data allowed us to determine the location of, extent, and time expended in fishing activities, and map these at a fine spatial scale. Duration of fishing trips and distance travelled, and an index of vessel dependency to particular fishing areas were also estimated at spatial scales more suited to SSF management than those currently used. However, our results also flag several issues that should be addressed in order for the methodology to be widely applicable for statutory fisheries management and marine planning purposes. 
373 The Longley Rice Irregular Terrain (LRIT) model provides a method for predicting the likely coverage of AIS reception by ground stations around Scotland. Further dedicated high resolution field verification is required to validate its utility, particularly in very near shore environments where local topography may impair VHF reception. Differences between predicted areas and recorded areas of AIS reception from vessels were evident in this study (e.g. Figure 1b). The base stations used were those officially licenced AIS transceivers registered with Ofcom (the UK regulator), therefore, the predicted range of reception is highly conservative as it does not take into account the numerous AIS receivers that provide AIS data but are not required to be licenced. Ofcom (the UK regulator) only requires AIS transceivers to be licenced and to provide technical information including the location of these devices [26]. Companies that harvest AIS data commercially acquire these data from various sources, including receivers for which no licence is required and there is little or no information upon which to model their reception range. The use of LRIT to plan and optimise the location and coverage of AIS receivers is worthy of further consideration if AIS is to be used for statutory or monitoring purposes.

Given the volumes of data likely to be generated by the large number of SSF vessels, it is important to consider the computational demands for dealing with these data. This study utilises freely available open source software such as POSTgresSQL, R, and QGIS together to process large volumes of AIS data on a single computer, which demonstrates the utility and cost effectiveness of these platforms. Storing of data and the application of quality control filters were efficiently conducted. The growing global community developing open source solutions [e.g. 32, 35] underpins the potential for spatial data to be analysed in both cost effective and in computationally efficient ways which could revolutionise the monitoring and management of SSF worldwide.

Data acquired for this study from commercially harvested sources of AIS data suggests that the sampling rate of the data provided by these suppliers may be variable (usually every 30 seconds, but $5-7$ minute intervals in some areas for unknown reasons). While some providers post-process AIS data using proprietary algorithms which contain assumptions that may render the data inappropriate for a specific analysis [19], the data provider contracted in this study supplied raw data files. However, data providers in turn, collate data from many other suppliers that use equipment ranging from major fixed assets operated by commercial companies, to home-made receivers and antennae. If AIS data is to be used for statutory purposes, the quality 
and provenance of these data needs to be of a standard that will bear scientific and legal scrutiny.

409

\subsection{AIS Data Utility in the context of SSF}

411

Individual fishing trips could be identified by applying a set of filtering criteria to the AIS data. In this study, criteria were necessary to discern fishing trips from non-fishing movements between ports or periods during which the vessel was transmitting its location but was in port. Consideration had to be given to tailoring the criteria to the specific fishery and allow for some regional variations depending on operational characteristics of the fleet (e.g. distance to port at the end of the trip). Region-specific approaches may be required to correctly identify fishing trips as shown for other fisheries using VMS, such as the commercial fishing vessels targeting walleye pollock (Gadus chalcogrammus) in the Eastern Bering Sea [36]. Although error rates in identifying fishing trips were low, methods could be refined. For example, while the majority of skippers reported predominantly using creels, about $10 \%$ of the vessels examined in the three AD reported occasionally switching to line and nets [28]. It would be useful to develop spatial methods to differentiate between tracks where different gears are being deployed. Moreover, linking fisher's logbook data to AIS information would improve the characterisation of a fishing trip in terms of gear used in that particular trip. Distinguishing between different 430 states or behaviours observed during a fishing trip such as steaming to fishing grounds, actively fishing, manoeuvring to retrieve snagged gear for example, would prove useful to identify the spatio temporal reference points needed to infer commercial fishing activity $[37,38]$ and should be further explored for different fishing gears in the context of SSF.

Trip duration and distance travelled were calculated to provide information on differences in SSF fleet activity, which could be useful for regional management measures. Over time, this information can highlight fishing patterns that may be a function of changes in species targeted and the abundance and location of target species [39]. Estimates of distance travelled could be used to estimate fuel costs and when combined with vessel characteristics such as size, engine capacity and value of catch, for example, estimates of profitability and fleet-scale economic viability could be assessed [40, 41].

Temporal and spatial changes in fishing activity levels were estimated at fine spatial scales from the AIS data collected. Vessels operating in the Outer Hebrides showed a greater average 
fishing activity than vessels in Fife and Shetland. This may be associated with longer fishing trips (both in duration and in distance covered) and associated higher fuel expenses. The spatial scales and temporal resolution of these fisheries data would depend on the questions addressed, and these would have to be discussed with the fishermen involved in order to maintain working relationships [42].

A metric of dependency on fishing location was developed using the MMSI number, which is a unique number that identifies a vessel. The level of dependency varied among regions, and revealed that in Fife, the number of vessels dependent on a particular fishing area was greater than in Shetland, despite the similar number of participating vessels from the two districts. This metric could aid managers in deciding when and where measures such as an exclusion zone during for example, the installation of marine devices such as wind turbines, or localised fishing restrictions would affect the least number of fishermen in each area. For many vessels, the number and location of fishing positions are quite limited. Several factors might be influencing these results such as vessel size, engine power or lack of facilities to process their catch which limit the distance they can travel in a given time and the range of weather conditions in which they can operate [43]. In combination, these factors could be used to predict potential displacement of fishing activities. Understanding these drivers would inform on the impacts of economic or legislative change on the fishing sector [44, 45] and allow regulators, legislators and the industry itself to act pre-emptively to buffer these effects, increasing resilience of SSF.

\subsection{Broader applications and future developments}

For open-access AIS data to be useful for statutory SSF fisheries management and marine planning purposes, AIS units would have to be fitted to either the entire fleet or a representative subset, to collect a statistically robust, set of statutory data. Receivers or logged data which are stored and forwarded through other forms of remote data transmission such as mobile telephone, must provide the necessary geographic coverage to ensure that data-loss is limited and near real time reporting would be plausible. In addition, transmitted and received data would need appropriate validation and quality control to meet minimum standards defined by the competent authority. AIS is not tamperproof, data can be falsified [46], entered in error, and these systems could be vulnerable to cyberattack. The AIS units will also need to remain active throughout the trip, unable to be switched off during fishing activity and be capable of 
retrospective reporting if switched to silent mode during fishing activity. In the absence of binding and enforceable regulation, it is unlikely that fishers will universally adopt and consistently use AIS. As AIS is principally designed as a collision avoidance system, it could be argued that using it for monitoring fishing activity and by extension compliance and enforcement of regulations, may undermine its use for safety purposes. Notwithstanding these caveats AIS is no more vulnerable than other methods of tracking fishing vessel activity and probably represents a low cost, accessible and an increasingly widely available data source.

The underlying driver for using AIS data to track vessel activity is that they are publicly 484 available, can be acquired at relatively low cost, and can be analysed robustly using lowpowered, open source computational analysis. Topographic and operational limits on the reception of AIS data can be overcome using store and forward capability utilising GSM and LEO satellite reception for example. In the future, the decreasing cost of these forms of data acquisition coupled with increasing deployment of the launch of $\sim 60$ low-cost micro- and nanosatellites planned in coming years [46] and the potential for in-port Wi-Fi data upload, suggests that a variety of relatively low-cost options for monitoring SSF will be feasible. Using available and developing technologies to capture and combine highly resolved fishing vessel tracks with operational and catch data is increasingly feasible. A suite of statistical methods [47] and the use of machine learning and data-mining techniques [48] are also developing apace and offer the potential to automatically interrogate and interpret AIS data to provide more comprehensive and up to date information to inform fisheries management and marine 497

Given the large number of vessels operating within SSF globally, a more comprehensive low cost and open source based approach to collecting fisheries management and marine planning related data may be worthy of consideration for this sector for the future. An end-to-end solution that empowers fishers to collect data that is of value to them and feeds into fisheries management and marine planning processes is potentially achievable. Global Positioning Systems and the spatio-temporal data they harvest can be transmitted through technologies ranging from mobile telephone, Wi-Fi and satellite networks at relatively low cost. New protocols with broader VHF Digital Exchange could supersede what is currently possible with AIS (e.g., VHF Data Exchange) [19] thus maintaining the potential for open access to data. Through the utilisation and adaptation of available technology, systems of lower cost with a minimal footprint suitable for use on the smaller vessels that characterise SSF could be 
designed. Numerous systems and protocols for recording and uploading catch data manually

510 already exist. The rapid expansion, ease of access and widespread use of open source software 511 and low-cost electronics suggests that data collection from SSF will become increasingly 512 automated. Policy makers, regulators and those involved in undertaking small scale fisheries 513 need to react swiftly to understand both the opportunities and challenges of adopting these 514 technologies and processes. Agreed data standards, interoperability and security of data will be 515 of particular importance. The rapid development of low cost and easily deployed technology 516 and processes is likely to have global reach in SSF and for the first time, may open up the 517 potential to monitor previously unregulated commercial and recreational fisheries. 518

Acknowledgements

520

521 This study was funded by the 2014/15 European Fisheries Fund 'Evidence Gathering in 522 Support of Sustainable Scottish Inshore Fisheries' (Grant Number: MI-NC-3-0093). Mark 523 James, Tania Mendo, and John Thompson were supported by the MASTS pooling initiative 524 (The Marine Alliance for Science and Technology for Scotland). Their support is gratefully 525 acknowledged. MASTS is funded by the Scottish Funding Council (grant reference HR09011) and contributing institutions. The research would not have been possible without the support of the 274 fishing vessel skippers who provided access to their vessels and data. Alex Farrant of CloudRF provided advice and helped to model the AIS radio frequency propagation. Jim Furness of Omni Marine Ltd., led the fitting of AIS units and provided invaluable technical advice. Thanks to Jim Watson and Nick Lake for helpful discussions and to the two anonymous reviewers, for their constructive comments which helped us improve the manuscript. 
References

535 [1] FAO, The State of World Fisheries and Aquaculture. 2014, Food and Agriculture Organisation of

[2] HLPE, Sustainable fisheries and aquaculture for food security and nutrition: A report by the high level panel of experts on food security and nutrition of the Committee on World Food Security, Rome, 2014, p. 119.

[3] C. Ehler, F. Douvere, Visions for a sea change. Report of the first international workshop on marine spatial planning. Intergovernmental oceanographic commission and man and the biosphere programme. IOC manual and guides, UNESCO, Paris, 2007, p. 83.

[4] European Commision, Directive 2008/56/ of the European Parliament and of the Council of 17 June 2008 establishing a framework for community action in the field of marine environmental policy (Marine Strategy Framework Directive), in: O.J.o.t.E. Union (Ed.) L164, 2008, pp. 19-40.

[5] I. Chollett, S.J. Box, P.J. Mumby, Quantifying the squeezing or stretching of fisheries as they adapt to displacement by marine reserves, Conservation Biology 30(1) (2016) 166-175. doi: 10.1111/cobi.12573

[6] M.S. Campbell, K.M. Stehfest, S.C. Votier, J.M. Hall-Spencer, Mapping fisheries for marine spatial planning: Gear-specific vessel monitoring system (VMS), marine conservation and offshore renewable energy, Marine Policy 45 (2014) 293-300. doi: 10.1016/j.marpol.2013.09.015

[7] J.G. Hiddink, S. Jennings, M.J. Kaiser, Assessing and predicting the relative ecological impacts of disturbance on habitats with different sensitivities, J. Appl. Ecol. 44(2) (2007) 405-413. doi:

$10.1111 / j .1365-2664.2007 .01274 . x$

[8] UNEP, Certification and sustainable fisheries, United Nations Environment Programme Division of Technology, Industry and Economics, Geveva, Switzerland, 2009, p. 116.

[9] G. Macfadyen, P. Salz, R. Cappell, Characteristics of small-scale coastal fisheries in Europe, European Parliament, Directorate-General for Internal Policies of the Union Brussels, 2011, p. 162. [10] A. Kafas, A. McLay, M. Chimienti, B.E. Scott, I. Davies, M. Gubbins, ScotMap: Participatory mapping of inshore fishing activity to inform marine spatial planning in Scotland, Marine Policy 79 (2017) 8-18. doi: 10.1016/j.marpol.2017.01.009

[11] NAFC Marine Centre, Shetland Islands' Marine Spatial Plan fourth edition, NAFC Marine Centre, 2014, p. 202.

[12] D.C. Dunn, K. Stewart, R.H. Bjorkland, M. Haughton, S. Singh-Renton, R. Lewison, L. Thorne, P.N. Halpin, A regional analysis of coastal and domestic fishing effort in the wider Caribbean, Fisheries Research 102(1-2) (2010) 60-68. doi: 10.1016/j.fishres.2009.10.010

[13] P. Breen, K. Vanstaen, R.W.E. Clark, Mapping inshore fishing activity using aerial, land, and vessel-based sighting information, Ices Journal of Marine Science 72(2) (2015) 467-479. doi: 10.1093/icesjms/fsu115

[14] N.A. Gribble, J.W.A. Robertson, Fishing effort in the far northern section cross shelf closure area of the Great Barrier Reef Marine Park: the effectiveness of area-closures, Journal of Environmental Management 52(1) (1998) 53-67. doi: 10.1006/jema.1997.0160

[15] S. Kavadas, I. Maina, D. Damalas, I. Dokos, M. Pantazi, V. Vassiloppoulou, Multi-Criteria Decision Analysis as a tool to extract fishing footprints and estimate fishing pressure: application to small scale coastal fisheries and implications for management in the context of the Maritime Spatial Planning Directive, 2015 16(2) (2015) 294-304. doi: 10.12681/mms.1087

[16] European Commision, Council Regulation (EC) No. 1224/2009 of 20 November 2009 establishing a Community control system for ensuring compliance with the rules of the Common Fisheries Policy., Official Journal of the European Union, 2009, pp. 1-50.

[17] R.L. Shelmerdine, Teasing out the detail: How our understanding of marine AIS data can better inform industries, developments, and planning, Marine Policy 54 (2015) 17-25. doi: 10.1016/j.marpol.2014.12.010

[18] F. Natale, M. Gibin, A. Alessandrini, M. Vespe, A. Paulrud, Mapping Fishing Effort through AIS Data, Plos One 10(6) (2015) 16. doi: 10.1371/journal.pone.0130746

[19] M.D. Robards, G.K. Silber, J.D. Adams, J. Arroyo, D. Lorenzini, K. Schwehr, J. Amos, Conservation science and policy applications of the marine vessel Automatic Identification System (AIS)-a review, Bulletin of Marine Science 92(1) (2016) 75-103. doi: 10.5343/bms.2015.1034 
[20] R.L. Shelmerdine, B. Leslie, A multidisciplinary approach to collection and use of VMS data from an inshore scallop fishery. NAFC Marine Centre. Report of Fishing Industry Science Alliance (FISA) project 04/12, Scottish Marine and Freshwater Science 6(13) (2015) 1-27. doi:

[21] O. Tully, Atlas of commercial fisheries for shellfish around Ireland, Marine Institute, 2017, p. 58.

[22] T. Russo, L. D’Andrea, A. Parisi, M. Martinelli, A. Belardinelli, F. Boccoli, I. Cignini, M. Tordoni, S. Cataudella, Assessing the fishing footprint using data integrated from different tracking devices: Issues and opportunities, Ecological Indicators 69(Supplement C) (2016) 818-827. doi: https://doi.org/10.1016/j.ecolind.2016.04.043

[23] F. Mazzarella, M. Vespe, D. Damalas, G. Osio, Discovering vessel activities at sea using AIS data: Mapping of fishing footprints, International Conference on Information Fusion (FUSION), Salamanca, Spain, 2014, pp. 1-7.

[24] MMO, Details of registered and licensed vessels over 10 metres and 10 metres and under, 2016. https://www.gov.uk/government/collections/uk-vessel-lists. (Accessed 10/05/2016).

[25] M.A. James, J. Thompson, Radio Frequency Propagation Mapping in Relation to the Use of Automatic Identification Systems (AIS) and Global System for Mobile communications (GSM) around the Scottish Coast. A report prepared for Marine Scotland, University of St. Andrews, 2015, p. 33.

[26] Ofcom, Ofcom Spectrum Information System / Ofcom spectrum management (WTR), 2016. http://spectruminfo.ofcom.org.uk/spectrumInfo/licences. (Accessed 12/07/2015).

[27] J.S. Seybold, Introduction to RF propagation, John Wiley \& Sons, Inc., New Jersey, United States of America, 2005.

[28] M.A. James, J.B. Thompson, A. McKnight, K. Orr, Gathering in Support of Sustainable Scottish Inshore Fisheries: Establishing the Location of Offshore Fishing Activities within Scottish Inshore Areas Using Appropriate Technology. , MASTS, 2015, p. 34.

[29] R Development Core Team. R: A language and environment for statistical computing. R Foundation for Statistical Computing, Vienna, Austria, 2016.

[30] J. Conway, D. Eddelbuettel, T. Nishiyama, S.K. Prayaga, N. Tiffin, RPostgreSQL: R Interface to the 'PostgreSQL' Database System. R package version 0.6-2, (2017). doi:

[31] Marine Scotland Science. Fish and Shellfish Stocks. 2016 Edition The Scottish Government, Scotland, 2016, p. 54.

[32] C. Calenge, The package "adehabitat" for the R software: A tool for the analysis of space and habitat use by animals, Ecological Modelling 197(3-4) (2006) 516-519. doi:

10.1016/j.ecolmodel.2006.03.017

[33] T. Duong, ks: Kernel Smoothing. R package version 1.10.6., 2017.

[34] G.M. Blundell, J.A.K. Maier, E.M. Debevec, Linear home ranges: effects of smoothing, sample size, and autocorrelation on kernel estimates, Ecological Monographs 71(3) (2001) 469-489. doi: 10.1890/0012-9615(2001)071[0469:LHREOS]2.0.CO;2

[35] F. Urbano, F. Cagnacci, Spatial Database for GPS Wildlife Tracking Data: A Practical Guide to Creating a Data Management System with PostgreSQL/PostGIS and R, Springer International Publishing2014.

[36] J.T. Watson, A.C. Haynie, Using Vessel Monitoring System data to identify and characterize trips made by fishing vessels in the United States North Pacific, Plos One 11(10) (2016) 1-20. doi: 10.1371/journal.pone.0165173

[37] D. Peel, N.M. Good, A hidden Markov model approach for determining vessel activity from vessel monitoring system data, Canadian Journal of Fisheries and Aquatic Sciences 68(7) (2011) 1252-1264. doi: 10.1139/f2011-055

[38] C. Charles, D. Gillis, E. Wade, Using hidden Markov models to infer vessel activities in the snow $\mathrm{crab}$ (Chionoecetes opilio) fixed gear fishery and their application to catch standardization, Canadian Journal of Fisheries and Aquatic Sciences 71(12) (2014) 1817-1829. doi: 10.1139/cjfas-2013-0572 [39] S. Bertrand, J.M. Burgos, F. Gerlotto, J. Atiquipa, Lévy trajectories of Peruvian purse-seiners as an indicator of the spatial distribution of anchovy (Engraulis ringens ), ICES Journal of Marine Science 62(3) (2005) 477-482. doi: 10.1016/j.icesjms.2004.12.002 
[40] T. Russo, A. Parisi, G. Garofalo, M. Gristina, S. Cataudella, F. Fiorentino, SMART: A spatially 642 explicit bio-economic model for assessing and managing demersal fisheries, with an application to 643 Italian trawlers in the Strait of Sicily, Plos One 9(1) (2014) 18. doi: 10.1371/journal.pone.0086222

644 [41] G. Tserpes, N. Nikolioudakis, C. Maravelias, N. Carvalho, G. Merino, Viability and management 645 targets of Mediterranean demersal fisheries: The case of the Aegean Sea, Plos One 11(12) (2016) 15. 646 doi: 10.1371/journal.pone.0168694

647 [42] R.L. Shelmerdine, R.J. Shucksmith, B. Mouat, Fisheries management in the context of shared 648 seas. A study commissioned by Fisheries Innovation Scotland (FIS), 2017, p. 58.

649 [43] K. Metcalfe, T. Collins, K.E. Abernethy, R. Boumba, J.-C. Dengui, R. Miyalou, R.J. Parnell, 650 K.E. Plummer, D.J.F. Russell, G.K. Safou, D. Tilley, R.A. Turner, H. VanLeeuwe, M.J. Witt, B.J.

651 Godley, Addressing uncertainty in marine resource management; combining community engagement 652 and tracking technology to characterize human behavior, Conservation Letters (2016) 460-469. doi: $65310.1111 /$ conl.12293

654 [44] Y. Vermard, P. Marchal, S. Mahevas, O. Thebaud, A dynamic model of the Bay of Biscay 655 pelagic fleet simulating fishing trip choice: the response to the closure of the European anchovy 656 (Engraulis encrasicolus) fishery in 2005, Canadian Journal of Fisheries and Aquatic Sciences 65(11) 657 (2008) 2444-2453. doi: 10.1139/f08-147

658 [45] J.E. Wilen, M.D. Smith, D. Lockwood, L.W. Botsford, Avoiding surprises: Incorporating 659 fisherman behavior into management models, Bulletin of Marine Science 70(2) (2002) 553-575. doi: 660 [46] D.J. McCauley, P. Woods, B. Sullivan, B. Bergman, C. Jablonicky, A. Roan, M. Hirshfield, K. 661 Boerder, B. Worm, Ending hide and seek at sea, Science 351(6278) (2016) 1148-1150. doi: 662 10.1126/science.aad5686

663 [47] Y. Vermard, E. Rivot, S. Mahevas, P. Marchal, D. Gascuel, Identifying fishing trip behaviour 664 and estimating fishing effort from VMS data using Bayesian Hidden Markov Models, Ecological 665 Modelling 221(15) (2010) 1757-1769. doi: 10.1016/j.ecolmodel.2010.04.005

666 [48] E.N. de Souza, K. Boerder, S. Matwin, B. Worm, Improving Fishing Pattern Detection from 667 Satellite AIS Using Data Mining and Machine Learning, Plos One 11(7) (2016) 20. doi: 668 10.1371/journal.pone.0158248 

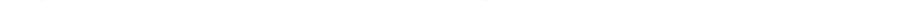


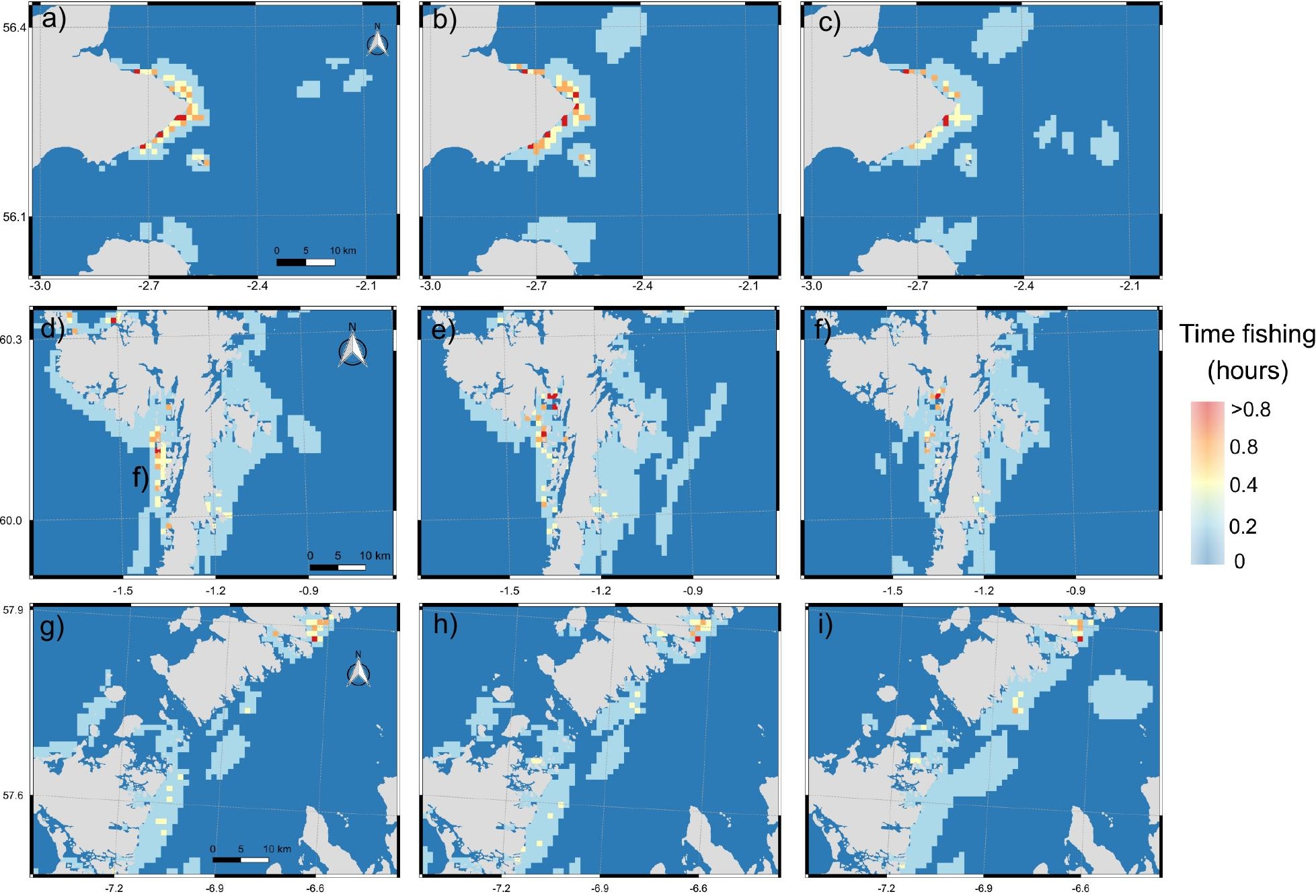


Table 1. Fishing activity levels (hours spent fishing) and numbers of vessels in each region during August, September and October 2015.

\begin{tabular}{|c|c|c|c|c|}
\hline Region & Month & $\begin{array}{l}\text { Average fishing } \\
\text { activity (hours) per } \\
\text { vessel }(\mathrm{CI})\end{array}$ & $\begin{array}{l}\text { Total fishing } \\
\text { activity (hours) }\end{array}$ & $\begin{array}{l}\text { Number of } \\
\text { vessels }\end{array}$ \\
\hline Fife & 8 & $21.11(14.25-28.20)$ & 399.6 & 19 \\
\hline Fife & 9 & $27.31(20.12-34.50)$ & 487.5 & 18 \\
\hline Fife & 10 & $18.67(11.81-25.52)$ & 317.4 & 17 \\
\hline Shetland & 8 & $29.86(16.39-43.32)$ & 507.6 & 17 \\
\hline Shetland & 9 & $30.23(17.38-43.09)$ & 544.2 & 18 \\
\hline Shetland & 10 & $22.22(10.71-33.73)$ & 400.0 & 18 \\
\hline Outer Hebrides & 8 & $35.60(28.16-43.05)$ & 1175.0 & 33 \\
\hline Outer Hebrides & 9 & $40.15(32.02-48.28)$ & 1445.6 & 36 \\
\hline Outer Hebrides & 10 & $35.81(26.34-45.29)$ & 1253.6 & 35 \\
\hline
\end{tabular}


1 Appendix A

2

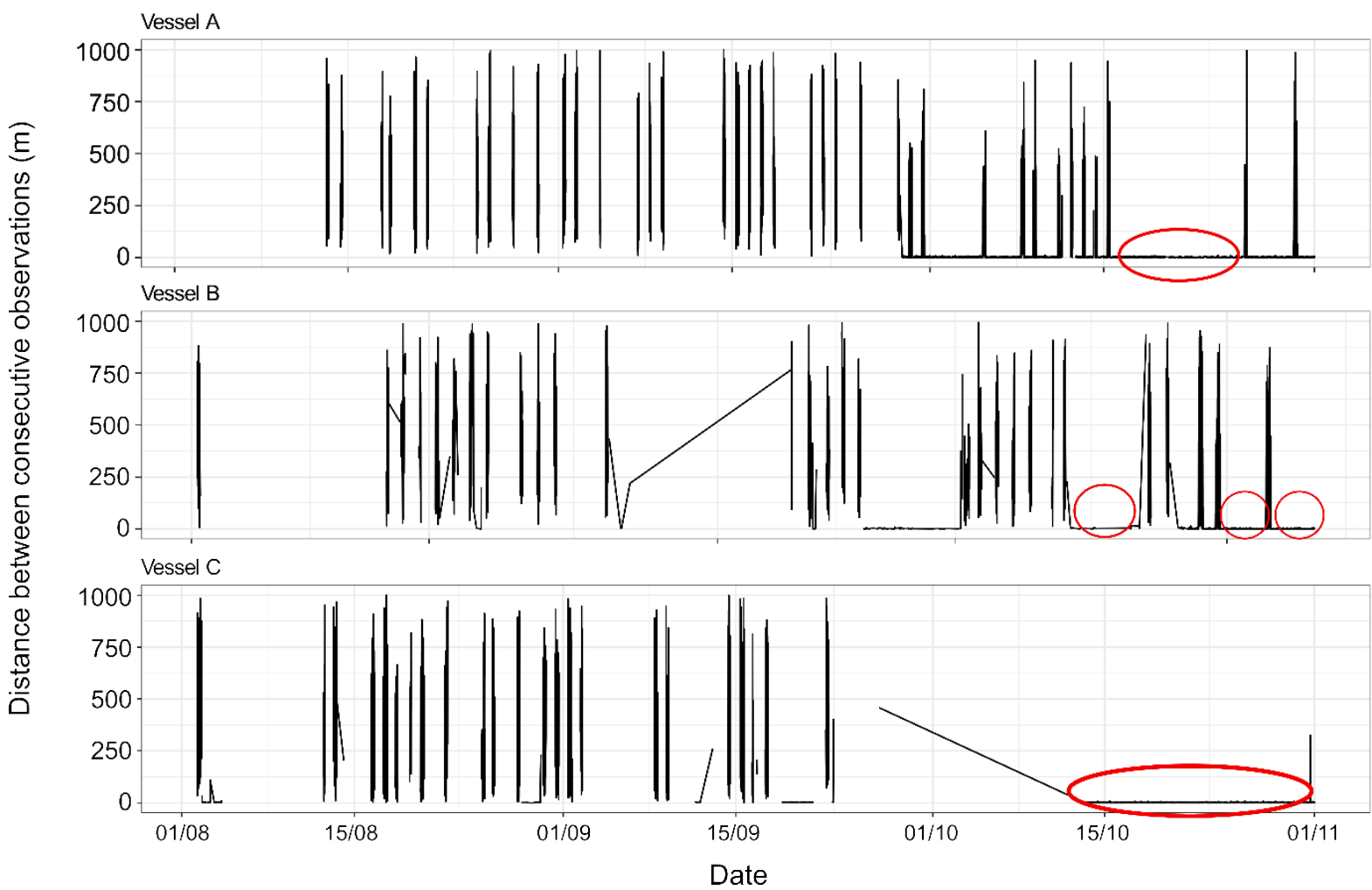

3 Fig. A1. Distance moved between two consecutive transmissions by vessels (i.e. A, B, and C)

4 from August to October 2015. Red circles indicate example of periods of no activity, when

5 AIS units were left turned on recording location in ports.

6

7 


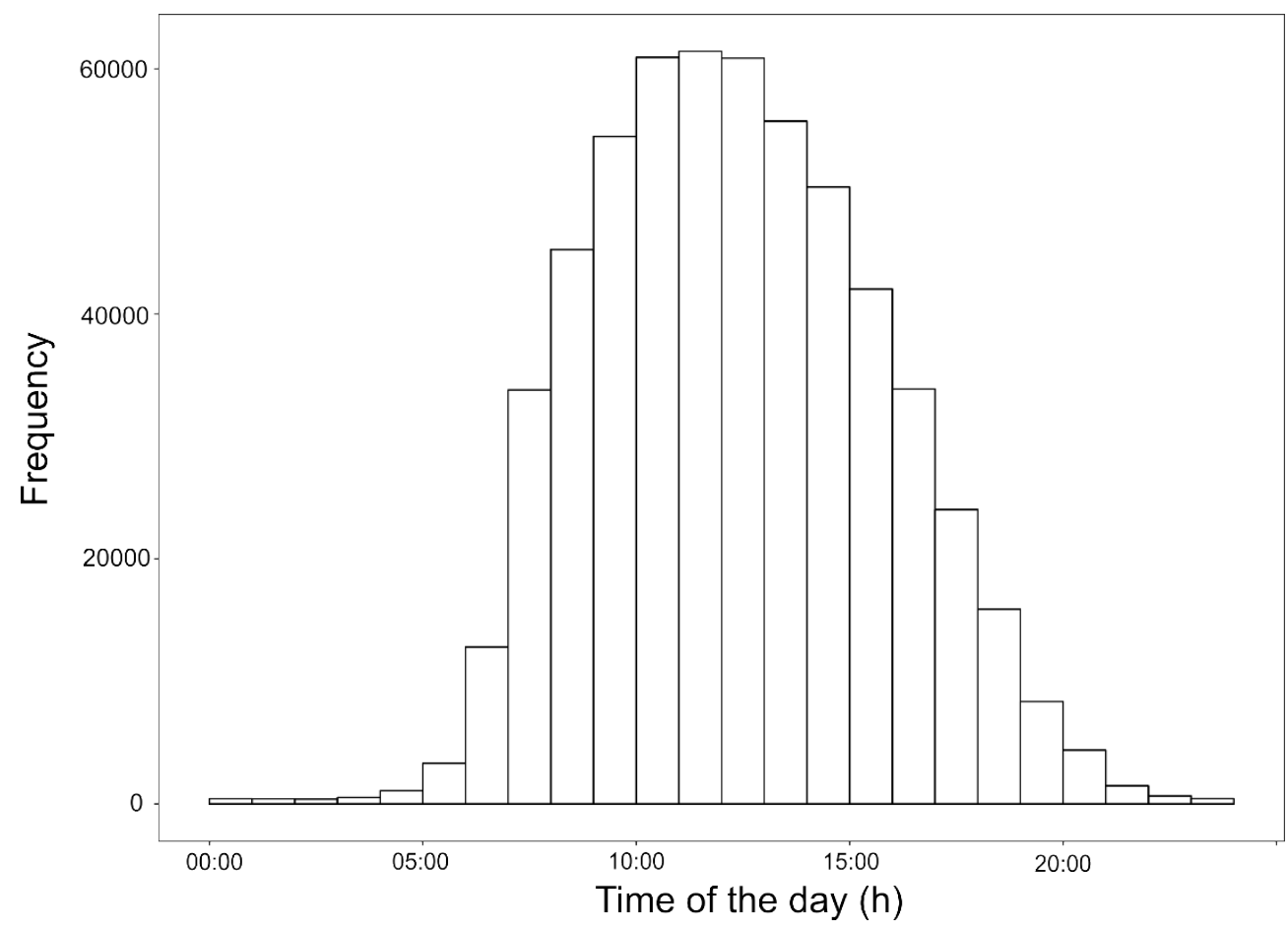

9 Fig. A2. Frequency of AIS observations (pooled for the three different Administrative

10 Districts) during hours of the day

11

12 
Observers conducted six trips on board of six different small scale fishing vessels using creels and pots and targeting lobsters (Homarus gammarus) and crabs (Cancer pagurus) or Norway lobsters (Nephrops norvegicus). Three trips were conducted in Stornoway AD and three trips in Anstruther AD. In each trip, the observer positioned a hand held GPS device in the cabin, which recorded position every 10 seconds. The observers registered the time the vessel spent either hauling gear, re-deploying or steaming. Target species was also recorded. The GPS tracks for these six trips are shown in Fig B1. Exploration of the frequency of speeds observed during hauling corroborated that a speed threshold of 3 knots was appropriate to separate fishing from non-fishing activities (Fig. B2).
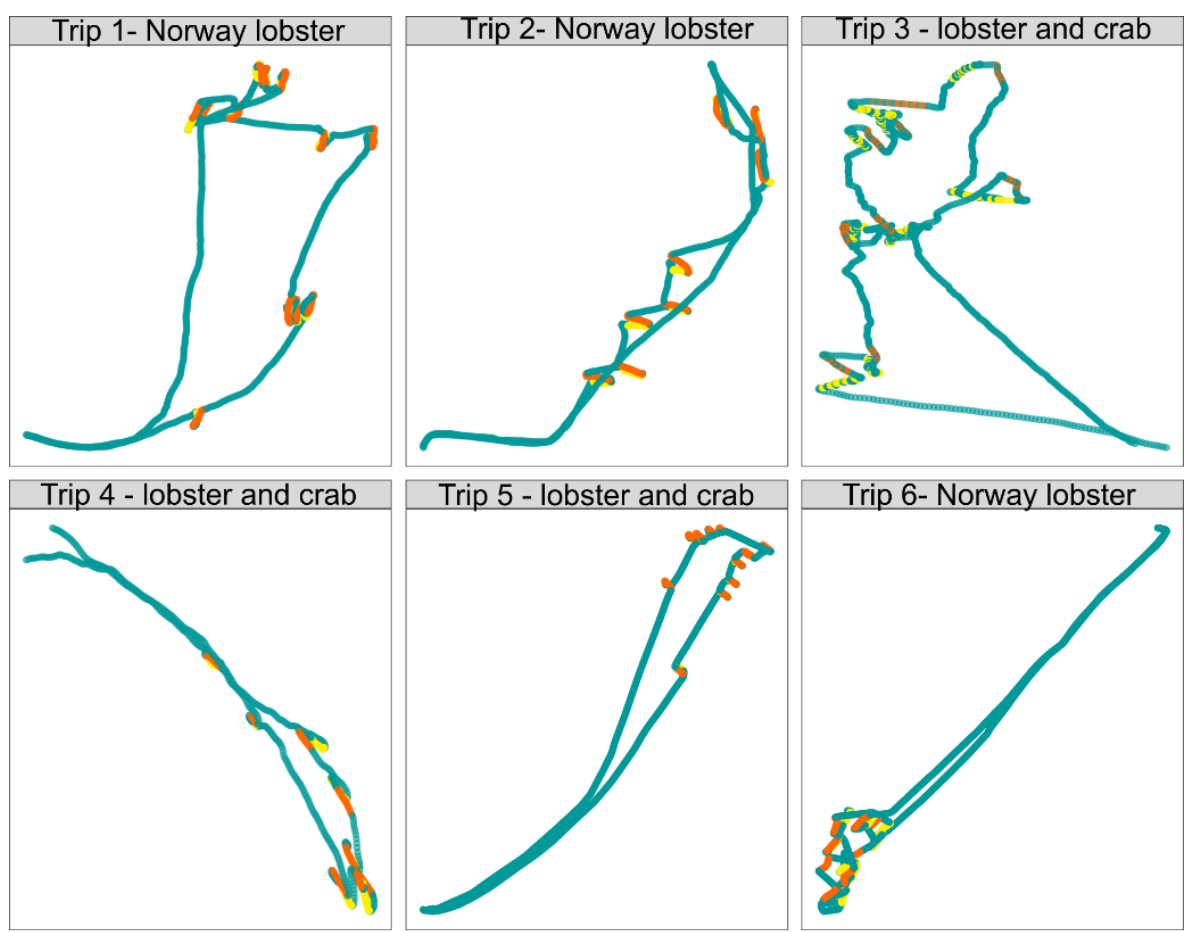

hauling

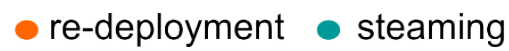

Fig. B1. GPS tracks recorded by on-board observers every 10 seconds showing hauling, redeployment and steaming activities during a fishing trip. Trips $1-3$ were conducted in vessels operating in Stornoway AD, and Trips 4 -6 were conducted in Anstruther AD. 


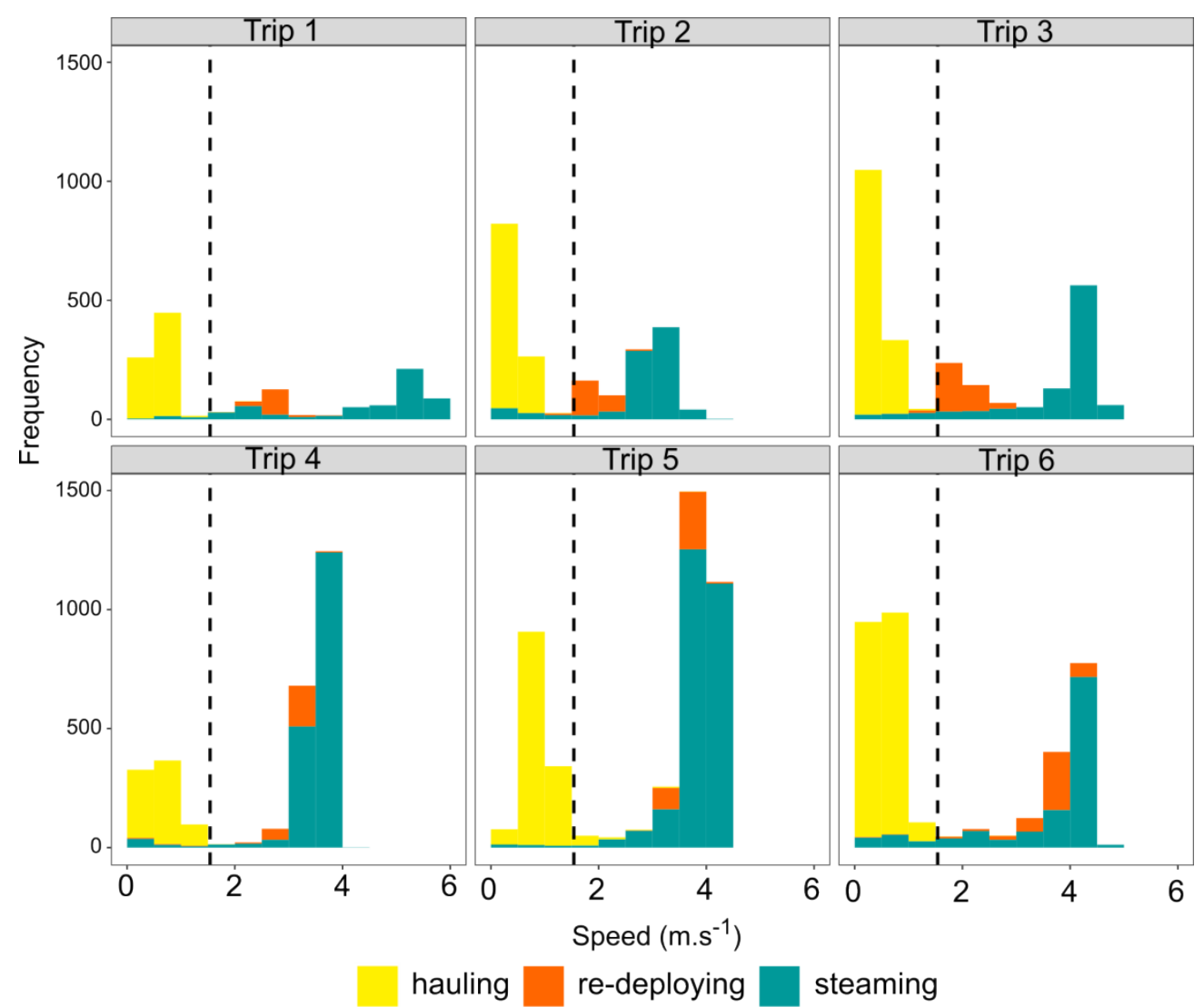

30 Fig. B2.Frequency distribution for speeds recorded during hauling, re-deployment of gear

31 (creels and pots), and steaming to fishing grounds. Vertical dashed lines represents the 3 knot value used to characterise fishing activities. 
33 Appendix C

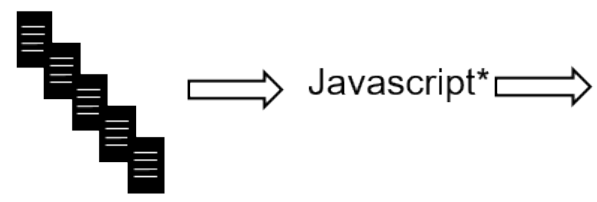

AIS data files
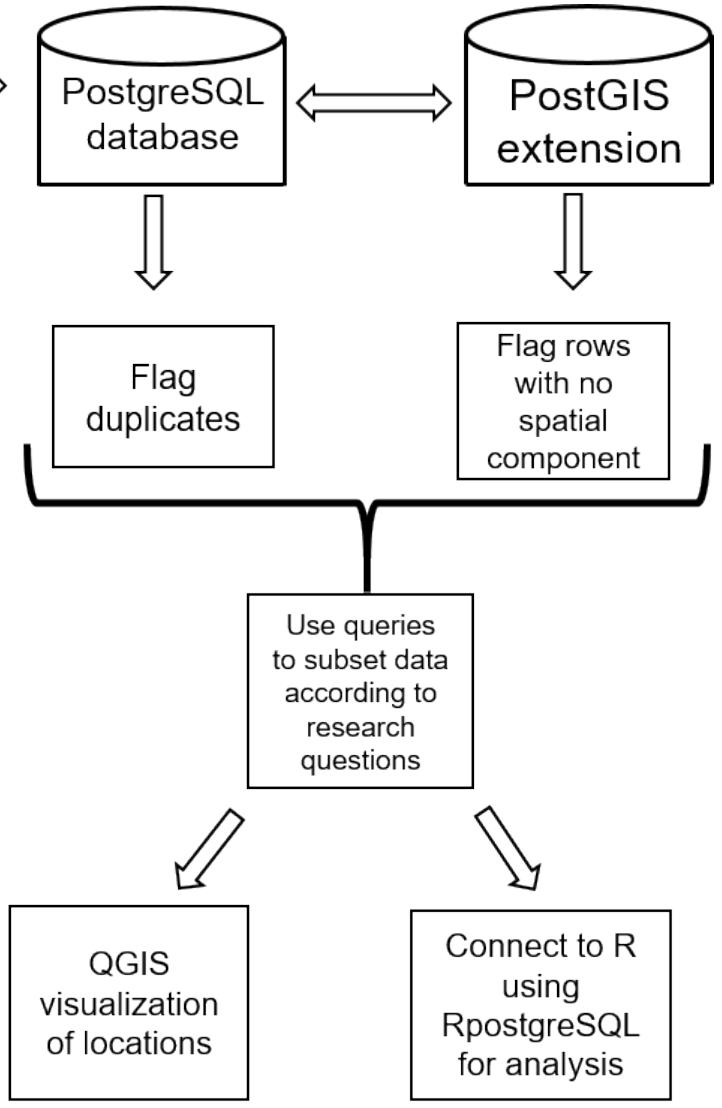

36 Fig. C1. General flow diagram of steps conducted to populate database and pre-processing of 37 AIS data. 
39 Table C1. Temporal performances (time required for computation) for each step conducted to 40 populate database and pre-processing of AIS data.

41

\begin{tabular}{lllc} 
Step & Tool & Size of dataset & $\begin{array}{l}\text { Time required } \\
\text { (minutes) }\end{array}$ \\
\hline $\begin{array}{l}\text { Transfer of }>13,000 \\
\text { csv files into unique } \\
\text { table in PostgreSQL } \\
\text { database }\end{array}$ & Javascript & $\begin{array}{l}3.7 \times 10^{7} \text { AIS } \\
\text { data rows }\end{array}$ & 360 \\
$\begin{array}{l}\text { Addition of a spatial } \\
\text { component }\end{array}$ & PostgreSQL and PostGIS & $\begin{array}{l}3.7 \times 10^{7} \text { AIS } \\
\text { data rows }\end{array}$ & 60 \\
$\begin{array}{l}\text { Flagging duplicates } \\
\text { based on time and } \\
\text { position and flagging } \\
\text { rows with no spatial } \\
\text { component }\end{array}$ & PostgreSQL and PostGIS & $\begin{array}{l}3.7 \times 10^{7} \text { AIS } \\
\text { data rows }\end{array}$ & 210 \\
$\begin{array}{l}\text { Subset data to three } \\
\begin{array}{l}\text { Administrative } \\
\text { districts (AD) }\end{array}\end{array}$ & PostgreSQL & & \\
$\begin{array}{l}\text { Dividing tracks into } \\
\text { separate fishing trips }\end{array}$ & $\begin{array}{l}\text { R, using the RpostgreSQL } \\
\text { interface, following the } \\
\text { methods described in main }\end{array}$ & $\begin{array}{l}1 \times 10^{6} \text { AIS data } \\
\text { rows }\end{array}$ & $\sim 45$ \\
& text & & \\
& & & \\
& &
\end{tabular}


45

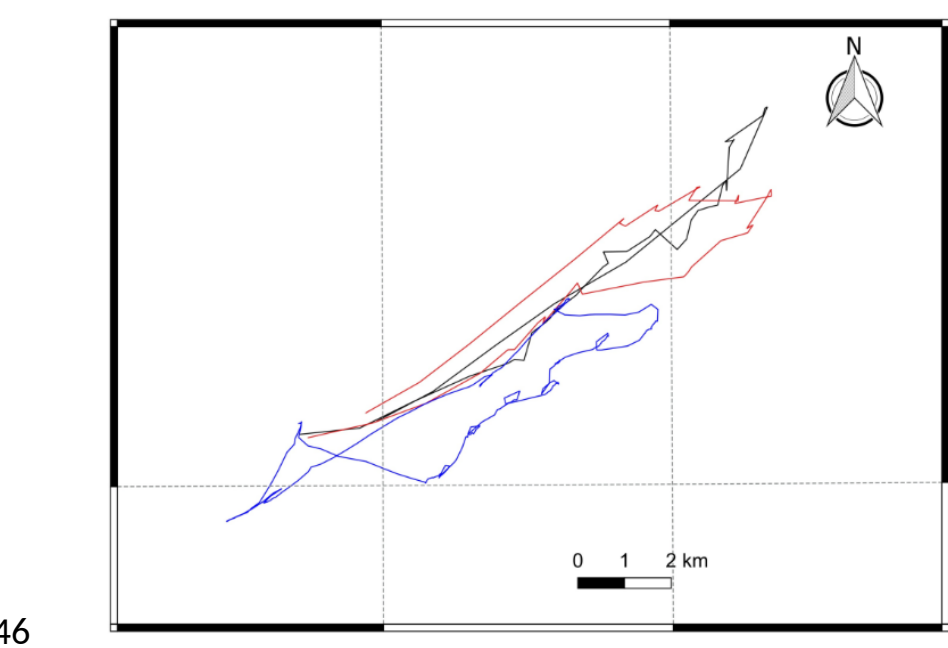

47

48 Fig. D-1. Identification of individual fishing trips for vessels operating in Anstruther

49 Administrative District. The characteristic looping pattern of static gear recovery is not

50 clearly visible (especially in the fishing trips represented by the black and the red lines). 
Figure captions

Fig. 1. Modelled AIS reception around Scotland. Registered AIS Base Stations and AtoNs (black points), modelled reception range of Base Stations and AtoNs (dark blue areas), modelled maximum range of AIS Class B vessel transmissions (light blue areas), Territorial Sea limit (12 NM, black line). A signal should be able to be received at $2 \mathrm{~m}$ Above Sea Level in the blue areas 99\% of the time. A: Fife, B: Outer Hebrides, C: Shetland, D: west of Skye, E: Moray Firth, F: Firth of Forth, G: north-west coast

Fig. 2a) Comparison between all AIS locations in Outer Hebrides (pink) and those retained after identification of fishing trips (overlaid grey points); b) Individual fishing trips showing a looping pattern characteristic of static gear recovery. Coastline and coordinates not shown to maintain vessel anonymity.

Fig. 3. Boxplot of a) mean trip duration (hours) and b) mean distance travelled per fishing trip by $\mathrm{AD}$. Interquartile range (boxes), median (bold lines), 95\% CI (bars), outliers (points). , significant differences between AD (small letters). Different letters above the bars indicate significant differences between regions.

Fig. 4. Maps of average fishing activities per vessel (hours per grid cell $1000 \mathrm{~m} \mathrm{x} 1000 \mathrm{~m}$ ) for each month (August, September and October) in (a-c) Fife, (d-f) Shetland, and (g-h) the Outer Hebrides. Same scale used across regions for visualization purposes.

Fig. 5. Total number of unique vessels counted in each grid cell $(1000 \mathrm{~m} \times 1000 \mathrm{~m})$ in each area for each month (August, September and October) in (a-c) Fife, (d-f) Shetland, and (g-h) the Outer Hebrides. Same scale used across regions for visualization purposes. 